\title{
The Semiotics of Contemporary Visual Texts: A Study in New Rhetorical Analysis
}

\begin{abstract}
Bishwo Raj Parajuli ${ }^{1}$
Abstract

This paper explores the semiotics of selected typical visual texts of our time and their implicatures. Some theoretical and conceptual tools for textual interpretation with regards to textual elements exist. However, contemporary visual texts are still prospective area of study. Considering such gap, I have chosen the visual texts that we encounter in our day to day and professional life. For delimitation purposes, only three types of visual communication events have been discussed, selected brochures of academic institutions, selected printed advertisements, and selected billboard advertisements. The analytical tools are predominantly critical discourse of the various motifs, images, structures and persuasive strategies used in the texts. The basic architecture of the discussion part is based on thick descriptions of the textual contents highlighting the semiotics of each. Findings of the study focus on semiotic implications and connotations of the key rhetorical elements. The major finding of the study is most of the visual texts principally try to glorify, glamorize and even exoticize the product or service. The conclusion derived is nothing like absolute conclusion. It is just an array of possible interpretations that pave path for a new discourse like-should we take them for granted? All in all, this is a new rhetorical analysis by outlook.
\end{abstract}

Keywords: New Rhetorical Analysis, Semiotics, Visual Texts,

\section{Introduction}

Semiotics is the study of sign system in popular arts and other contemporary forms of communication. This practice has taken the firmest hold in approaches to any form of popular culture like movies, television programmes, women's magazine and tabloids, billboard and printed ads and so on (Green\& Lebihan, 2011).

Since the sign systems in semiotics are non-linguistic, they demand special cross-cultural understanding of different walks of life, paralinguistic clues and cues, and an array of visual language among many others. For instance, if a boss wants to cut off his manual work force through automation technology, the technology or medium of change itself can be a powerful message.

A prominent media analyst Marshall McLuhan states that disproportionate use of technology and automation technology in twentieth and twenty first century is not just an indicator of development, this tendency is leading us towards a menacing age of mechanization. We are bound to destroy the role of human work force and human association in works. In the words of McLuhan, “... it was not the machine, but what one did with the machine, that was its meaning or message (2000)" This is exactly the point where comparatively novel and pragmatic subjects like technical communication are interested.

Practically technical communication activities have been running through ages, probably beginning with the morn of human civilization. The primitive frescos and hieroglyphics for some kind of coded information are ancient form of technical communication activities. Similarly, Aayurvedas, Manusmriti (The Laws of sage Manu), and architectural designs of our ancestors like Araniko etc are other examples our ancient technical communication texts (Adhikari \& Upadhyaya, 2014). So much so that even current medical prescriptions of the physicians are also a kind of technical communication. 
Thanks to illegible handwritings of doctors, we do not have to bother to decode their sign systems; only the pharmacists can read them.

Communication theorists Gerson and Gerson opine that technical communication is oral and written communication for and about business and industry. It focuses on communicating about products and serviceshow to manufacture them, market then, deliver them, and use them (Gerson and Gerson, 2014).

In this context, one of the interesting questions that trigger our mind is: how do the manufactures design to communicate through a subtle semiotic system? And what are the implications and objectives of such semiotic system? This research paper deals with typical events of technical communication and study implicatures of the major signs (as codes of visual communication) from a new rhetorical analysis point of view.

\section{Data and Methodology}

This paper tries to explicate some typical technical communication events focusing on some contemporary visual texts. For delimitation purposes, only three types of representative technical communication texts have been selected. They are representative in the sense that they appear more patternized, frequent, popular and communicative in the present context. So, methodologically, it is convenient sampling. Thick descriptions based on in-depth observation of the selected communication acts will be followed by content analysis. As a whole, the texts will be scrutinized from post structural outlook like new rhetorical analysis.

\section{New Rhetorical Analysis : A Theoretical Review}

Rhetorical analysis is a form of criticism with a long tradition shared by scholars from various disciplines. The general focus of rhetorical analysis is to arrive methodically at insights into the performance of a communication event (or assemblage of events) through an investigation of selected features of the event. Rhetorical analysis, therefore, offers scholars a principled approach to describe how communication works in a given instance.

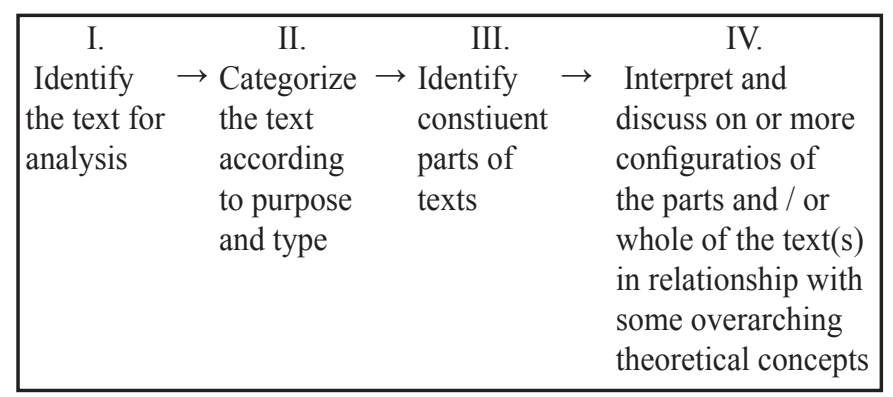

Figure I: Basic Approach in Rhetorical Analysis

Rhetorical analysis focuses on the textual components and effects of those components on the perception of the person experiencing it.

There are three waves in rhetorical criticism: traditional, new rhetorical and critical post modern. However, the so-called new rhetorical and critical postmodern theorists climb upon the shoulder of classical theorist Aristotle and try to de- canonize the established ways of interpreting the structurally and strategically functioning constituents of texts.

Referring to Aristotle's conception about rhetoric, Mark Zachry defines: rhetoric is the use of artful language based means to affect belief. Individuals persuade others through three means: the character or credibility of the source of information (ethos), the stirring of emotions in the individual being persuaded (pathos) and proof of truth through reasonable arguments (logos). Theoretically, these three means of persuasion are popularly known as rhetorical appeals.

Aristotle has also offered classical approaches of rhetorical performance. Rhetoric can be deliberative, forensic and demonstrative or epideictic $(2009$, p.71).

Deliberative rhetorical performances are concerned with questions like what should be done is a given situation or deciding future courses of actions.

Forensic approach focuses on establishing what is just and unjust through judicial deliberations about things. And, demonstrative or epideictic form of rhetoric is concerned with demonstrating or establishing the merits of something for the public.

In the first half of twentieth century, rhetorical criticism as such was de-canonized as communication got more 
complex due to the advancement in industry, science, technology and complicated human relationship. Due to such insights, some theorists considered it as New Rhetorical criticism. This approach is rather a post structural school of criticism rather than individual promulgation of a theorist.

In the second half of twentieth century and throughout twenty first century, almost every walk of human life has been guided by post modern thoughts-obviously including rhetorical criticism. Especially, deconstructionist view believes that meaning is possible only because of privileged use of language and its arbitrary system that guides us to perceive things according to some logocentric symbolization. Thus, a deconstructionist reading of a text subverts its apparent significance by uncovering contradictions and conflicts within it.

In this paper, rather than interpreting a text or act of communication from structural or formulaic perspectives, we shall create an array of meanings for critiquing purpose and look at them from new rhetorical perspective. For discussion purpose only, selected printed visual texts which can be typically labeled as technical communication, have been presented below.

\section{Discussion of the Selected Studies}

\section{Study 1: Tertiary level brochures}

Now-a-days, it is fashionable as well as ritualistic for academic institutions, especially tertiary and university level colleges to print attractive brochures in glossy booklet forms. Perhaps this is due to the influence of commodification ideology. It is a tell-tale fact that institutions and organizations are judged even on the basis of glamour and quality of the brochure. Just like glamour tabloids and magazines, these publications also aim to glamorize and glorify their selling points.

The masterminds of these texts seem to be interested to glamorize good looking students. A good look of face and anatomy is always a hot selling commodity for fastgrowing consumerism. Business houses and industrialist understand this fact very well. So, it is quite common and expected tendency that people from fashion industry and mass media use (and even exploit) skinny and sensuous models and celebrities to advertise their products. In the present context, education has become mother business of all other businesses. Following the footsteps of other business people, educationists are also using beauty and fanciful presentation of college teenagers in their prospectus.

This tendency was identified after a thorough study of selected brochures over a couple of years (See Exhibit 1, Appendix). Then the focal images were sorted into four groups- images of female student models, images of male student models, mixed images and others. Majority of the images were that of girl students. Almost all the major images in these brochure pages are restricted to three Bs coined as 'Bold, Big and Beautiful' by Kaul (2014).

\section{Study 2: Print ads cuts}

This is the age of media. Especially popular mass media like social networking sites (facebook, instagram etc.), radio, television programmes, music videos, cinemas, daily newspapers, glamour tabloids, etc. have created a vibe in modern generation and they are considerably successful in brainwashing the mindset of consumers through visual appeals created by human anatomy and face. Especially, print media is notorious in creating media blitz by glamorizing the commonplace and changing it into paramount. In terms of model selection, these advertisements pay more attention to stereotyped images and gender roles. For instance, their first priority is upon fair complexioned skinny models, beautiful housewives. At the bottom of their list is a gentleman with a common apparition. Their basic motive is glorification of the commodities through celebrity endorsement and sensuous models. In other words, plump, short of height, dark skinned or anyone with deformity (as the majority of people think) would hardly fit as models in these cases.

\section{Study3: Billboard ads}

Billboard advertisements are not very much different from print advertisements and college brochures. A typical formula or motif in billboard is using a colossal image of a celebrity model (preferably a female) as focal image and placing it somewhere where majority of the public 
can have eye contact. It is an attempt of looming over onlookers' visual selection. Furthermore, in the words of Rutherford, photographs do not necessarily indicate size; some photographs show the objects (referring to the models) next to something common. This is also known as technique of juxtaposition and amplification (Rutherford 2006). Recently, full page photograph of an acclaimed political leader in Nepal was published in most of the national newspapers (See Exhibit 3 in Appendix) and huge billboards in different parts of the city. This unusually celebrated coverage of an acclaimed political leader throughout the media houses and entry points of the town was not a common phenomenon. It was an attempt of stereotyping a celebrated political leader as a hero. The way the leader was projected as a hero or messiah of nation building was questioned by many skeptics. However, from communication point of view, this gigantic projection of a leader who emerged from grassroots level is something like McLuhan's maxim'Medium is the message'. To rephrase it in a better coinage of McLuhan, it is a hot medium. According to McLuhan, "A hot medium is one that extends one single sense in high definition. High definition is the state to being well filled with data. A photograph is visually high definition (2000, p.30)." So this particular publicity of a political leader is a good example of how media can be used as hot or cold to influence the perceptions of audience.

Furthermore, the billboard or even printed advertisements as such are full of semiotic implications. In the eyes of semioticians, they underlie distinct myths and their structural connotation is distinct. Either they follow social norms or violate social norms. According to the structural analyst John Fiske- "...widely accepted conventions are close to the norms. The unexpected, the non conventional is a deviation from the norm" (1990, p. 101). For example, in Exhibit 3, the halo behind the head of the leader and the semiotics of red color scheme are connotative of the non conventional and deviation from the norm. In other words, it is an attempt of creating a myth of a revolutionary hero.

\section{Conclusion}

Language is ineffable means to express human emotions

The Semiotics of Contemporary Visual Texts:

A Study in New Rhetorical Analysis and feelings despite its pivotal role in successful communication. A visual language is more expressive than written scripts or verbal mode of communication. The verbal mode of communication, i.e. language, has its own limitations. After all language can not express everything we want to convey. What we aim to convey gets conveyed more nonverbally than verbally. So the designers of the discussed communication events have focused on using non-verbal signs of mass persuasion to attract the audience. In general following tendencies can be observed in these texts:The patterns and configuration of the matters are important in the act of communication. They reflect culture and quality through pictures, archives, location and statistics. Even paper and printing quality can not be ignored; After all, medium is the message. However, credibility and acceptability of the asserted messages are always questionable.

- Mostly these texts focus less on written contents. Major focus is given to visual and graphical appeal. Their basic motive is to loom over the visual selection of the onlookers through sensuous appeal. Only a few of them are able to create aesthetical appeal.

- There are attempts to project charisma in the model; and these charismatic projections happen in stereotyped forms. For instance, they have used a traditional concept of a hero or a model.

- Using McLuhan's terminologies, these texts of technical communication are rich in hot medium of message. However, in Aristotelian rhetorical paradigm, one would grade them as poor in ethos, pathos and logos. Moreover, they are less forensic, slightly deliberative and more demonstrative in nature.

- These pieces aim to create some structural myths such as- A leader as a hero, a model or celebrity as a true brand ambassador of the products in their hands, girls or good looking students as the messenger of success and so on. All these semiotics and stereotyped concepts can be critically examined from New rhetorical point of view. 


\section{References}

Adhikari, D. \& Upadhyaya, .(2014), Technical Communication. Kathmandu: Buddha Publications.

Fiske, J. (1990). Introduction to Communication Studies. New Delhi:Routledge.

Gerson, S. \& Gerson, S. (2014). Communication: Process \& Product. New Delhi: Pearson.

Green, K. \& Lebihan, J. (2011). Critical theory \& practices. New Delhi: Routledge.

Kaul, A. (2014). Business Communication. Delhi: PHI.
Lois, T. ( 2006) Critical Theory Today. Routledge: India.

McLuhan, M. (2000). Understanding Media. Media Studies. CDE, TU: Kathmandu.

Rutherford, Andrea J. (2006). Basic Communication Skills for Technology. Pearson India.

Zachry, M. (2009). Rhetorical Analysis. The Handbook of Business Discourse (ed. by Chiappini, Francesca $\quad$ B.) Edinburgh: Edinburgh University Press.

\section{Appendix}
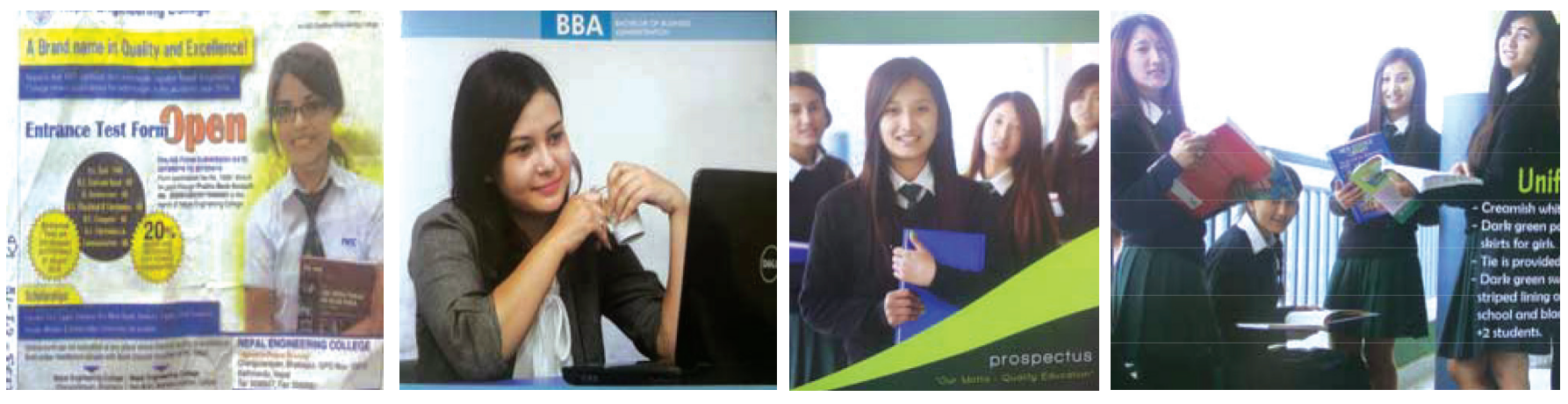

Exhibit 2

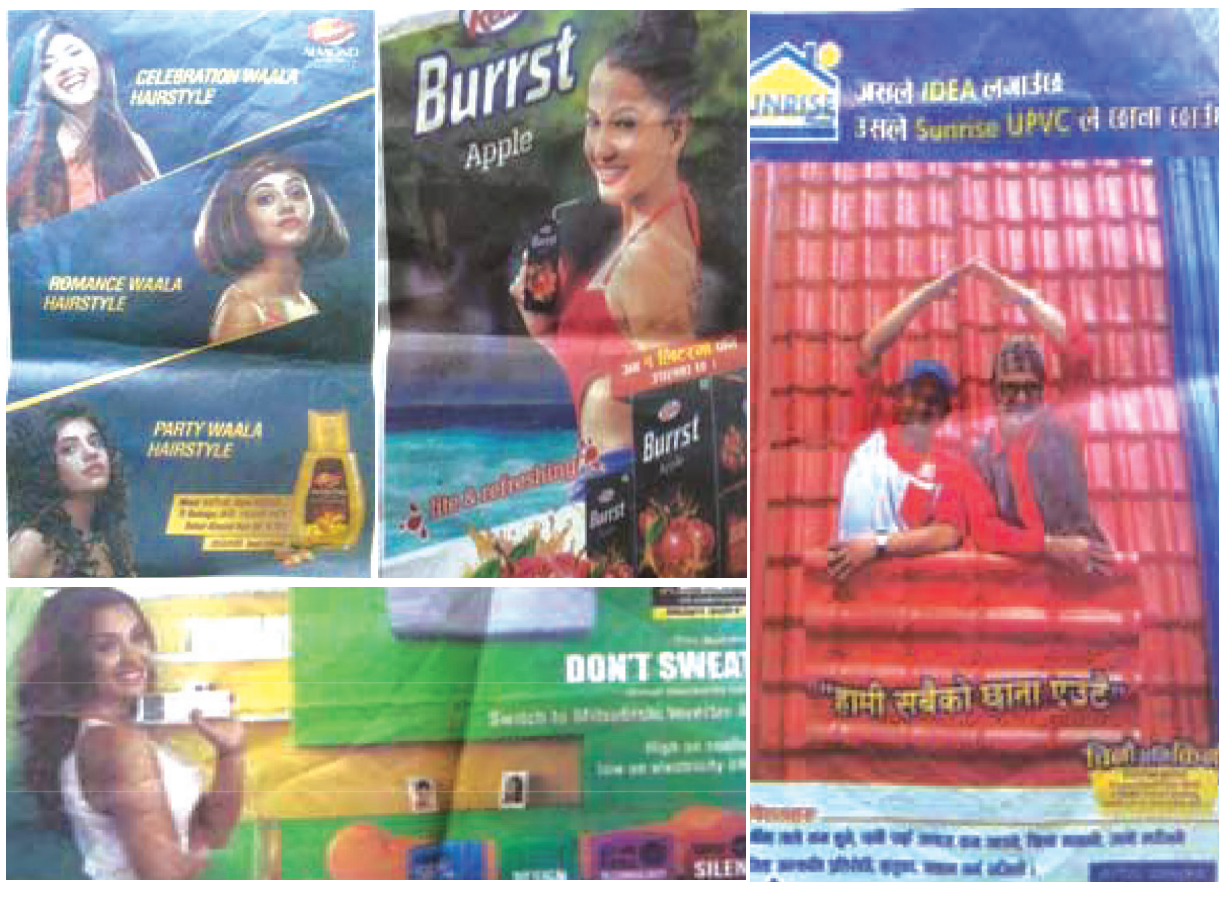

Exhibit 3

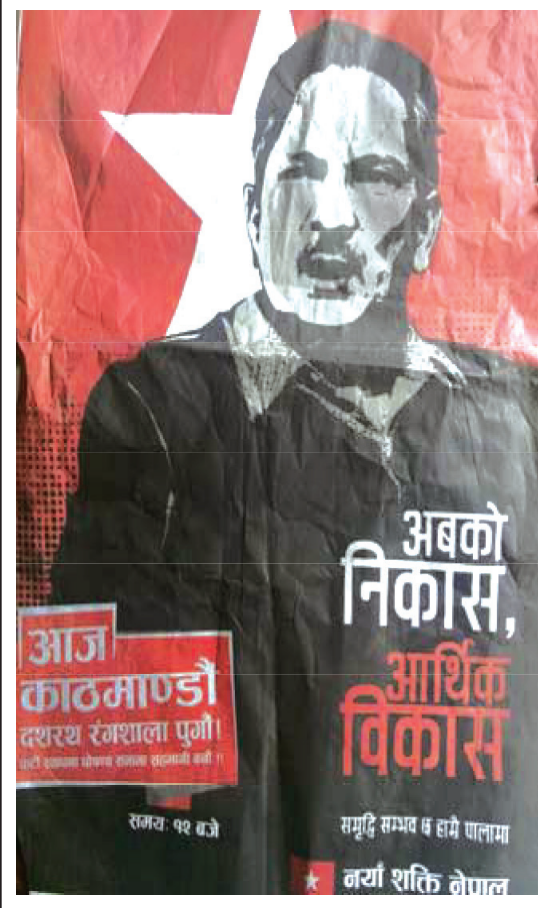

